\title{
Effects of Aging on Urinary Secretion of 3-Hydroxyproline and its Importance for Cancer Screening in The Elderly with ROC Analysis
}

\author{
Angelo J.G. BOS*, Ping YUAN*, Akie MARUTA**, \\ Shigeo MATSUYAMA**, Masao ARAI* and Isao OKAZAKI* \\ ${ }^{*}$ Department of Community Health, Division of Community Health and Environmental Medicine, \\ School of Medicine, University of Tokai, Isehara \\ ${ }^{* *}$ Central Research Laboratory, National Defense Medical College, Tokorozawa
}

\begin{abstract}
Objective: to observe the influence of aging on urinary secretion of 3-hydroxyproline (3-Hyp) in normal subjects and in cancer patients and study the effects of aging on the accuracy of urinary 3-Hyp as a general-purpose cancer screening test.

Design: We reanalyzed, from the aspect of gerontology, the amounts of 3-Hyp in the urine samples of the 211 healthy persons and 94 patients with cancer reported earlier. The two groups were divided in 3 age subgroups: adult, 30 to 44 years, middle-aged, 45 to 64 years, and aged, 65 years and older. The cancer stage was separated into 3 categories: stage 1 , the early stage without any invasion, stage 2 , locally invasive with no distant metastasis, and stage 3 , advanced cancer. The correlation of age and urinary 3-Hyp was analyzed in normal subjects and cancer patients. Sensitivity and specificity were calculated for different cutoff points in the diverse groups to construct the receiver operating characteristic (ROC) curves.

Main Results: We observed that aging decreases the urinary secretion of 3-Hyp in normal subjects, with a correlation coefficient of $-0.250(\mathrm{p}<0.001)$. The mean levels of urinary 3-Hyp in patients with cancer were significantly higher than in the normal subjects, $p=0.005$. The correlation coefficient of urinary 3-Hyp and age was not significant $(0.100)$ in cancer patients. The cutoff points of $0.800 \mathrm{mg} / \mathrm{g}$ creatinine of urinary 3-Hyp for persons under 65 years of age and $0.600 \mathrm{mg} / \mathrm{g}$ creatinine for persons 65 years or older were the best thresholds for cancer screening. In the ROC analyses, we observed that 3 -Hyp has higher accuracy for cancer screening in the aged group for all stages together and in the aged and middle-aged for early stages of cancer.

Conclusions: The urinary 3-Hyp test was more effective for cancer screening in old persons (65 years or older), where cancer is more frequent and more difficult to discover. The authors stress the necessity and importance of verifying the effectiveness of urinary 3-Hyp for general cancer screening in a larger population and in a community set.
\end{abstract}

Key Words: Cancer screening (がん検診), Urinary 3-hydroxyproline(尿中 3-ハイドロキシプロリン), The elderly（高齢者)，ROC analysis（ROC 分析）, Sensitivity and specificity（鋭敏度および特異 度)

\section{Introduction}

Cancer has been the leading cause of death among the Japanese population since $1981^{1}$. Approximately $64 \%$ of all cancer deaths in 1991 occurred in persons aged 65 years and over ${ }^{11}$.
Furthermore, the figures on cancer occurrence have shown a decreasing tendency for the leading malignant neoplasms in Japan. The mortality of gastric cancer is decreasing not only in Japan ${ }^{2}$ but also in the USA and Europe ${ }^{3}$. Moreover, cancers of the uterus, liver and esophagus have been decreasing in Japanese

Reprint requests to: Isao OKAZAKI, M.D., Ph.D., Department of Community Health, School of Medicine, Tokai University, Bohseidai, Isehara, Kanagawa, 259-11 Japan 
women ${ }^{2}$. However, the mortality of cancer in general is increasing, mainly among the aged ${ }^{2}$. In this context a mass screening test for cancer should not target only the most prevalent cancer sites ${ }^{4}$. Currently, however, most oncogenic markers are limited to organ specific cancers ${ }^{5,6)}$ and their effectiveness for screening cancer in the elderly is unknown ${ }^{7}$. Thus, a nonorgan-specific mass screening, also suitable for the elderly, is necessary.

Measurement of the urinary 3-hydroxyproline (3-Hyp) level has been reported for use in a general screening test for all cancers sites ${ }^{8)}$. It is an amino acid found primarily in type IV collagen, the main component of extracellular membranes ${ }^{9)}$, and is eliminated in the urine ${ }^{10)}$. The elevation of the excretion of 3-Hyp is related to increased catabolism of collagen ${ }^{8,9}$. Cancer leads to the destruction of extracellular membranes, inducing an increase in urinary elimination of $3-\mathrm{Hyp}^{8}$. As the metabolism of collagen decreases with aging ${ }^{11}$, it is expected that the normal urinary excretion of endogenous 3-Hyp should also decrease. With a lower metabolic rate of collagen, the destruction of collagen by cancer invasion in the elderly should provoke a bigger and faster alteration than in other age groups. In a reevaluation of our earlier report, we examined the influence of aging on the urinary excretion of endogenous 3 -Hyp in normal subjects (control group) and in cancer patients, and its influence on the effectiveness of urinary 3-Hyp in screening for cancer in general.

\section{Material and Methods}

\section{Control group}

As the control group we used 211 persons with ages ranging from 31 to 83 years; 140 were men and 71 women. The control group was selected from among 997 persons who submitted to medical examination for a health check-up, at a special center, the Shin-Akasaka Clinic, in Tokyo. From the total, 768 were excluded for having abnormal results in the medical examination. Of the remaining 229, 3-Hyp could not be measured in 18 persons due to a low concentration in the urine with an urine creatinine level of less than $60 \mathrm{mg} / \mathrm{dl}$; therefore they were also excluded from the study, as reported previously ${ }^{8)}$. The medical examination included physical examination, blood pressure, chest x-ray, gastrofluoroscopy, abdominal echography, blood lipid and hepatic function-marker analysis, serum creatinine, fasting serum glucose, hematologic examination, and past and current history of disease inquiry. More detailed specification of the health check-up examination and its results have already been published ${ }^{8)}$. The urine samples were obtained at the day of the medical examination and stored without preservatives in a freezer at $-20^{\circ} \mathrm{C}$, until analysis.

\section{Cancer-patient group}

The cancer patients were 94 inpatients of the Keio University Hospital. Two patients from the previously reported group were excluded, because they did not fit in the age-group classification used in the present study. Fifty-one of the 94 patients were males and 43 females. They ranged in age from 32 to 83 years, with different stages and sites of cancer (Table 1). In the case group, the most prevalent cancer was of the stomach (51 persons), while 43 persons had other cancers. The cancer diagnoses were histologically confirmed in all cases. Using the same criteria as described in our previous paper ${ }^{8)}$, the group was classified into 3 stages as follows: stage 1, early cancer, without any invasion of surrounding structures or detectable metastasis; stage 2, local invasive cancer without distant metastasis and stage 3 , advanced cancer. Cancer-patient-group urine samples were collected prior to any oncologic treatment (surgery or drug prescription), and stored in the same manner as the control-group samples.

Cases and controls were classified by age into 3 groups: adult (from 31 to 44 years), middle-aged (45 to 64 years) and aged (65 years and over), as shown in Table 2. We also compared the efficacy of urinary 3-Hyp testing for the stomach cancer with that for the other cancers.

\section{Urine sampling and analysis}

To avoid the effect of dietary 3-Hyp we collected the first fasting spot urine of all subjects. The 3-Hyp was measured using an Hitachi amino acid auto analyzer, corrected for the urinary creatinine level 
Table 1 Cancer distribution by site and stage.

\begin{tabular}{|c|c|c|c|c|c|c|c|c|c|}
\hline \multirow{2}{*}{ Cancer Site } & \multirow{2}{*}{$\frac{\text { Stage unknown }}{\mathrm{N}^{*} \%}$} & \multicolumn{2}{|c|}{ Stage 1} & \multicolumn{2}{|c|}{ Stage 2} & \multicolumn{2}{|c|}{ Stage 3} & \multicolumn{2}{|c|}{ total $(\%)$} \\
\hline & & $\mathrm{N}$ & $\%$ & $\mathrm{~N}$ & $\%$ & $\mathrm{~N}$ & $\%$ & $\mathrm{~N}$ & $\%$ \\
\hline Stomach & $9 \quad 18$ & 13 & 25 & 11 & 22 & 18 & 35 & 51 & 53 \\
\hline Liver & $2 \quad 29$ & 1 & 14 & & -- & 4 & 57 & 7 & 7 \\
\hline Colon & $2 \quad 18$ & 2 & 18 & 6 & 55 & 1 & 9 & 11 & 12 \\
\hline Lung & --- & 2 & 40 & 2 & 40 & 1 & 20 & 5 & 5 \\
\hline Breast & --- & 3 & 30 & 6 & 60 & 1 & 10 & 10 & 10 \\
\hline Others & 330 & 1 & 10 & 1 & 10 & 5 & 50 & 10 & 10 \\
\hline Total & $16 \quad 17$ & 22 & 23 & 26 & 28 & 30 & 32 & 94 & 100 \\
\hline
\end{tabular}

${ }^{*} \mathrm{~N}$ : number of persons.

Table 2 Age-group distribution of cancer patients and the control group.

\begin{tabular}{lrrrrrr}
\hline \multirow{2}{*}{ Age Group } & \multicolumn{2}{c}{ Cancer Patients } & & \multicolumn{2}{c}{ Control Group } \\
\cline { 2 - 3 } \cline { 5 - 6 } & N & $\%$ & & & N & $\%$ \\
\hline Adult & 14 & 15 & & 85 & 40 \\
Middle-aged & 54 & 57 & & 112 & 53 \\
Aged & 26 & 28 & & 14 & 7 \\
Total & 94 & 100 & & 211 & 100 \\
\hline
\end{tabular}

${ }^{*} \mathrm{~N}$ : number of persons.

and expressed in $\mathrm{mg} / \mathrm{g}$ of creatinine, as described previously ${ }^{8}$. The reproducibility of the determination of 3-Hyp in urine samples has been reported ${ }^{8)}$. The variation was within $3 \%$ in day-to-day examinations.

\section{Statistical methodology}

The mean value, standard deviation (s.d.), linear regression analysis and correlation coefficient calculations were performed using a statistic software package (FISHER Version.1.2 Copyright of Computer Medical Laboratory, Tokyo, Japan) on an NEC98 (Nippon Electronic Company 9800 series, Tokyo, Japan) personal computer. We used the numeric values (1, 2 and 3 ) of each cancer stage to verify the difference of stage distribution among the various age groups. Student's t test was used to verify the statistical significance between different results. The sensitivity and false-positive rates (1-specificity) as well as the positive predictive value, were measured for different cutoff points for all age groups, for different stages, and also for stomach and other cancers. Sensitivity was calculated as [true positive/(true positive + false negative) $] \times 100$ and the false positive rate as $\{1-$ [true negative/(true negative + false positive) $]\} \times 100$. The positive predictive value was computed as [true positive/(true positive + false positive) $] \times 100$.

We plotted the paired sensitivity/false positive rate of the diverse cutoff points in different groups in a graph and drew ROC curves, as described by Egan $^{12)}$, based on measurement of the area under each curve using a graphic processor. The area under the ROC curve, which reflects the accuracy of the test performed $^{13)}$, was measured by the method of Hanley and $\mathrm{McNeil}{ }^{14)}$ and expressed as area \pm s.d.\%.

\section{Results}

Effects of age on urinary excretion of 3-Hyp in healthy subjects

The mean value of urinary 3-Hyp for all 211 healthy persons was $0.277 \pm 0.245 \mathrm{mg} / \mathrm{g}$ creatinine. The scatter diagram with the regression line (Figure 1) of age and urinary 3-Hyp shows a significant decrease in the excretion of this amino acid with the increase of age in the control group. The correlation coefficient was $-0.250(\mathrm{p}<0.001)$. 


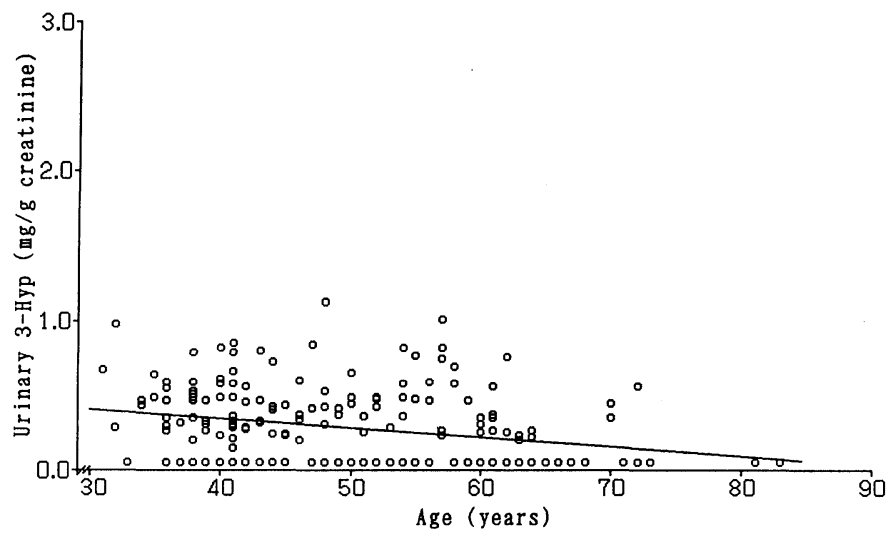

Fig. 1 Regression line of age and urinary 3-Hyp in healthy subjects. Urinary 3-Hyp= $0.600-0.060 \times$ Age; Correlation coefficient $=-0.250(p<0.001)$

Table 3 Mean values of urinary $3-\mathrm{Hyp}$ in $\mathrm{mg} / \mathrm{g}$ creatinine of the control group, separated by sex and age group.

\begin{tabular}{|c|c|c|c|}
\hline \multirow[b]{2}{*}{ Sex } & \multirow[b]{2}{*}{ Age group } & \multicolumn{2}{|c|}{ Urinary 3-Hyp } \\
\hline & & $\mathrm{N}$ & $\mathrm{m} \pm \mathrm{s} . \mathrm{d}$ \\
\hline \multirow{4}{*}{ All } & Adult & 85 & $0.330 \pm 0.240^{*}$ \\
\hline & Middle-aged & 112 & $0.256 \pm 0.247^{* *}$ \\
\hline & Aged & 14 & $0.144 \pm 0.166$ \\
\hline & Total & 211 & $0.278 \pm 0.245$ \\
\hline \multirow{4}{*}{ Male } & Adult & 51 & $0.318 \pm 0.225^{*}$ \\
\hline & Middle-aged & 77 & $0.240 \pm 0.220^{* *}$ \\
\hline & Aged & 12 & $0.126 \pm 0.154$ \\
\hline & Total & 140 & $0.259 \pm 0.224$ \\
\hline \multirow{4}{*}{ Female } & Adult & 34 & $0.347 \pm 0.259$ \\
\hline & Middle-aged & 35 & $0.291 \pm 0.295$ \\
\hline & Aged & 2 & $0.252 \pm 0.192$ \\
\hline & Total & 71 & $0.317 \pm 0.278$ \\
\hline
\end{tabular}

*Significantly different between adult and middle-aged groups, $\mathrm{p}<0.05$, and between adult and aged groups, $\mathrm{p}<$ 0.005 . **Significantly different between middle-aged and aged groups, $\mathrm{p}<0.05$.

$\mathrm{N}$ : number of persons in the subgroup; $\mathrm{m} \pm$ s.d.: mean \pm standard deviation.

The comparison of the amount of urinary 3-Hyp in the different age groups, is shown in Table 3. The adult group showed the highest mean of urinary 3-Hyp, with $0.330 \pm 0.240 \mathrm{mg} / \mathrm{g}$ creatinine. The differences from the other groups were statistically significant, with $\mathrm{p}<0.05$ for the middle-aged and $\mathrm{p}<0.005$ for the aged group. The middle-aged group, present- ed a mean of $0.256 \pm 0.247 \mathrm{mg} / \mathrm{g}$ creatinine, significantly higher than the aged group, $0.144 \pm 0.166 \mathrm{mg} / \mathrm{g}$ creatinine $(\mathrm{p}<0.05)$ (Table 3$)$.

The males presented a correlation coefficient between urinary 3-Hyp and age of $-0.315(\mathrm{p}<0.001)$, and women -0.110 ( $\mathrm{p}$ was not statistically significant - N.S.). Males also had significant differences among the results of urinary 3-Hyp by age group. The adult males had the highest mean value of 3-Hyp, $0.318 \pm 0.225 \mathrm{mg} / \mathrm{g}$ creatinine, with $\mathrm{p}<0.05$ compared with the middle-aged and $p<0.005$ compared with the aged. The middle-aged presented a mean of $0.240 \pm$ 0.220 , significantly higher than the aged group, $0.126 \pm 0.154 \mathrm{mg} / \mathrm{g}$ creatinine, $\mathrm{p}<0.05 \quad$ (Table 3). Although the difference among the age groups was not statistically significant, the women demonstrated the same pattern with the mean value of urinary 3-Hyp decreasing by age group: $0.347 \pm 0.259,0.291 \pm$ 0.295 and $0.252 \pm 0.192 \mathrm{mg} / \mathrm{g}$ creatinine, respectively for adult, middle-aged and aged groups (Table 3 ).

Effect of aging on the urinary excretion of 3-Hyp in cancer patients

The mean value of urinary 3-Hyp was significantly higher, in the 94 cancer patients than in the normal subjects: $1.388 \pm 6.263(\mathrm{p}<0.005)$. Two women, with advanced stages of cancer of the pancreas and melanoma, presented urinary 3-Hyp results of over $20.000 \mathrm{mg} / \mathrm{g}$ creatinine, while the others were all under $3.000 \mathrm{mg} / \mathrm{g}$ creatinine. The linear regression analysis 


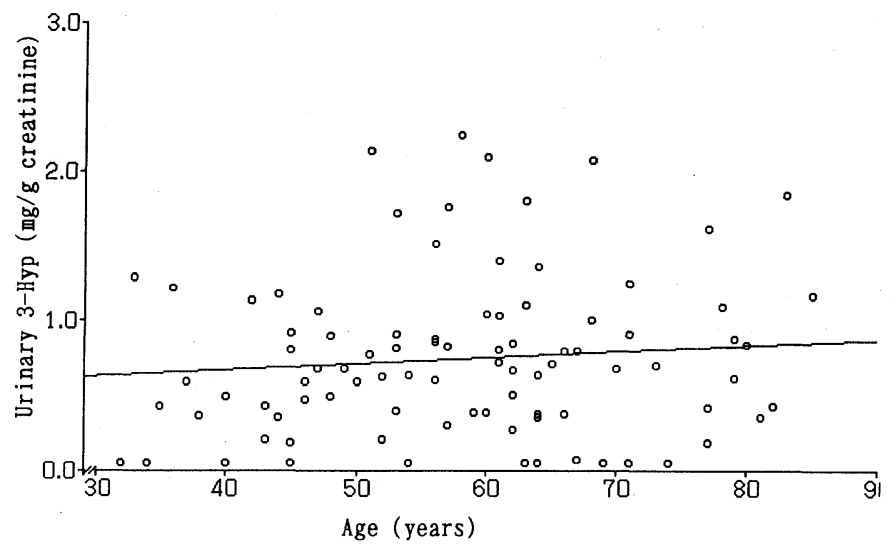

Fig. 2 Regression line of age and urinary 3-Hyp in cancer patients, excluding two patients with results of 61 and $20 \mathrm{mg} / \mathrm{g}$ creatinine. Urinary $3-\mathrm{Hyp}=0.500+0.004 \times$ Age; Correlation coefficient $=0.100$ ( $p=$ N.S.)

Table 4 Differences of cancer stage distribution* among age groups.

\begin{tabular}{|c|c|c|c|c|c|c|}
\hline \multirow[b]{2}{*}{ Sex } & \multicolumn{2}{|r|}{ Adult } & \multicolumn{2}{|c|}{$\begin{array}{l}\text { Age group } \\
\text { Middle-aged }\end{array}$} & \multicolumn{2}{|r|}{ Aged } \\
\hline & $\mathrm{N}$ & $\mathrm{m} \pm \mathrm{s} . \mathrm{d}$ & $\mathrm{N}$ & $\mathrm{m} \pm \mathrm{s} . \mathrm{d}$ & $\mathrm{N}$ & $\mathrm{m} \pm \mathrm{s} . \mathrm{d}$ \\
\hline All & 11 & $1.82 \pm 0.83$ & 47 & $2.10 \pm 0.86$ & 24 & $2.21 \pm 0.70$ \\
\hline Male & 2 & $2.00 \pm 1.00$ & 26 & $2.00 \pm 0.92$ & 19 & $2.27 \pm 0.68$ \\
\hline Female & 9 & $1.78 \pm 0.79$ & 21 & $2.24 \pm 0.75$ & 21 & $2.11 \pm 0.74$ \\
\hline
\end{tabular}

${ }^{*}$ The numeric values of stage classification (values 1, 2 and 3 for stages 1, 2 and 3, respectively) were used to calculate the mean and standard deviation of the cancer stage.

$\mathrm{N}$ : number of patients; $\mathrm{m} \pm$ s.d.: mean \pm standard deviation.

of age and urinary 3-Hyp results showed an almost horizontal line with a correlation coefficient of -0.070 ( $p=$ N.S.). However, when the 2 discrepant values were excluded the correlation coefficient became positive, 0.100 ( $\mathrm{p}=$ N.S.), as shown in Figure 2 .

Table 4 shows that there were no statistic differences in stage distribution among the age groups.

The difference in the average of the results of urinary 3-Hyp among the age groups did not show the same pattern as in the healthy persons, the highest value was in the middle-aged, $1.937 \pm 8.253$, while the adult value was $0.564 \pm 0.436$ and that for the aged was $0.731 \mathrm{mg} / \mathrm{g}$ creatinine, without statistical significance (Table 5).

Male cancer patients had a positive correlation coefficient between age and urinary 3-Hyp results: 0.070 ( $p=$ N.S.). The mean values of urinary 3 -Hyp presented in Table 5 show a significant difference between the adult male group, with $0.250 \pm 0.125 \mathrm{mg} / \mathrm{g}$ creatinine and the middle-aged males with $0.775 \pm$ $0.604, \mathrm{p}<0.05$. The aged group presented a mean of $0.584 \pm 0.384 \mathrm{mg} / \mathrm{g}$ creatinine in men.

Linear regression analysis between age and urinary 3-Hyp in females showed a correlation coefficient of $-0.060 \quad(p=N . S$.$) , but, excluding the two$ discretely bigger values, it turned positive, $0.180(\mathrm{p}=$ N.S.). In the female fraction, the mean values of 3 -Hyp were $0.689 \pm 0.452,3.503 \pm 12.456$, and $1.009 \pm 0$. 666 , respectively for adult, middle-aged and aged groups. These differences were not significant (Table 5).

The 51 patients with stomach cancer presented a urinary 3-Hyp result of $0.735 \pm 0.599 \mathrm{mg} / \mathrm{g}$ creatinine on the average, which was not significantly lower 
than the average of the 44 remaining patients with other cancers: $2.553 \pm 9.504 \mathrm{mg} / \mathrm{g}$ creatinine.

Effects of aging on the accuracy of urinary 3-Hyp as a cancer screening test (ROC analyses)

The paired sensitivity/specificity ratios for dif-

Table 5 Mean values of urinary $3-\mathrm{Hyp}$ in $\mathrm{mg} / \mathrm{g}$ creatinine of cancer patients, by sex and age group.

\begin{tabular}{|c|c|c|c|}
\hline \multirow[b]{2}{*}{ Sex } & \multirow[b]{2}{*}{ Age group } & \multicolumn{2}{|c|}{ Urinary 3-Hyp } \\
\hline & & $\mathrm{N}$ & $\mathrm{m} \pm \mathrm{s} . \mathrm{d}$ \\
\hline \multirow{4}{*}{ All } & Adult & 14 & $0.564 \pm 0.436$ \\
\hline & Middle-aged & 54 & $1.937 \pm 8.253$ \\
\hline & Aged & 26 & $0.731 \pm 0.539$ \\
\hline & Total & 95 & $1.388 \pm 6.263$ \\
\hline \multirow{4}{*}{ Male } & Adult & 4 & $0.250 \pm 0.125^{*}$ \\
\hline & Middle-aged & 31 & $0.775 \pm 0.604$ \\
\hline & Aged & 17 & $0.584 \pm 0.384$ \\
\hline & Total & 52 & $0.672 \pm 0.538$ \\
\hline \multirow{4}{*}{ Female } & Adult & 10 & $0.689 \pm 0.452$ \\
\hline & Middle-aged & 23 & $3.503 \pm 12.456$ \\
\hline & Aged & 9 & $1.009 \pm 0.666$ \\
\hline & Total & 43 & $2.252 \pm 9.217$ \\
\hline
\end{tabular}

*Significantly different between adult and middle-aged groups, $\mathrm{p}<0.05$.

$\mathrm{N}$ : number of persons in the subgroup; $\mathrm{m} \pm$ s.d.: mean \pm standard deviation. ferent cutoff points with their predictive values in different age groups are shown in Table 6. The cutoff point of $0.800 \mathrm{mg} / \mathrm{g}$ creatinine had a specificity of $97 \%$, a sensitivity of $29 \%$ and a positive predictive value of $57 \%$, for the adult group, while the middleaged group had a specificity of $96 \%$, sensitivity of $46 \%$, and predictive value of $83 \%$. Using the same cutoff of $0.800 \mathrm{mg} / \mathrm{g}$ creatinine, the aged group presented the best specificity $(100 \%)$, but a lower sensitivity (38\%). However, using a more moderated threshold, $0.600 \mathrm{mg} / \mathrm{g}$ creatinine, the aged group showed a sensitivity of $62 \%$ with a specificity of $100 \%$. Using the 0.600 threshold for the adult group, the specificity decreased to $87 \%$ and the predictive value to $27 \%$, while for the middle-aged the specificity was $91 \%$, sensitivity $61 \%$ and predictive value $77 \%$.

ROC curves for all stages of cancer (Figure 3) showed the aged-group curve figures in the upper level, with an area of $85 \pm 5.9 \%$ followed by the middle-aged with an area of $83 \pm 3.8 \%$, and, in the lower curve, the adult group with $64 \pm 8.8 \%$. The ROC curves for stage 1 cancer (Figure 4) showed a clear difference between the adult group, and the others. The aged and middle-aged groups showed a small difference. The areas under ROC curves for

Table 6 Specificity, sensitivity and positive predictive values of diverse cutoff points of urinary 3 -Hyp in $\mathrm{mg} / \mathrm{g}$ creatinine, for cancer screening, in the different age groups.

\begin{tabular}{|c|c|c|c|c|c|c|c|c|c|}
\hline \multirow{2}{*}{ Cutoff } & \multicolumn{3}{|c|}{ Adult } & \multicolumn{3}{|c|}{$\begin{array}{c}\text { Age group } \\
\text { Middle-aged }\end{array}$} & \multicolumn{3}{|c|}{ Aged } \\
\hline & Spec & Sens & Pred & Spec & Sens & Pred & Spec & Sens & Pred \\
\hline 0.100 & 32 & 79 & 16 & 51 & 89 & 47 & 79 & 81 & 87 \\
\hline 0.200 & 34 & 79 & 16 & 51 & 87 & 46 & 79 & 77 & 87 \\
\hline 0.300 & 46 & 71 & 18 & 64 & 83 & 53 & 79 & 77 & 87 \\
\hline 0.400 & 62 & 57 & 20 & 73 & 72 & 56 & 86 & 69 & 90 \\
\hline 0.500 & 78 & 43 & 24 & 86 & 70 & 70 & 93 & 62 & 94 \\
\hline 0.600 & 87 & 29 & 27 & 91 & 61 & 77 & 100 & 62 & 100 \\
\hline 0.700 & 92 & 29 & 36 & 93 & 50 & 77 & 100 & 54 & 100 \\
\hline 0.800 & 97 & 29 & 57 & 96 & 46 & 83 & 100 & 38 & 100 \\
\hline 0.900 & 99 & 29 & 80 & 98 & 31 & 89 & 100 & 31 & 100 \\
\hline 1.000 & 100 & 29 & 100 & 98 & 28 & 88 & 100 & 27 & 100 \\
\hline 1.100 & 100 & 29 & 100 & 99 & 20 & 92 & 100 & 19 & 100 \\
\hline 1.200 & 100 & 14 & 100 & 100 & 20 & 100 & 100 & 15 & 100 \\
\hline
\end{tabular}

Each value represents the percentage. Spec: specificity, Sens: sensitivity, Pred: Positive predictive value. 


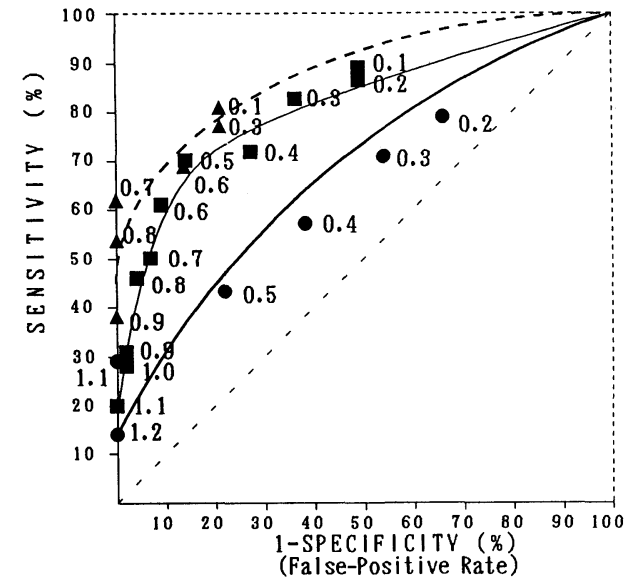

Fig. 3 ROC curves of urinary 3 -Hyp for different age groups in all stages of cancer. Each value indicates the cutoff point of 3 - $\mathrm{Hyp}$ in $\mathrm{mg} / \mathrm{g}$ creatinine of adult $(\bullet)$, middleaged $(\square)$ and aged $(\Delta)$ groups. All values were rounded off from 3 decimal places to 1 decimal place for clarity. Curves indicate the ROC curves of adult $(-)$, middle-aged $(-)$, and aged (---) groups. The percentages of the areas under the ROC curves in adult, middleaged and aged persons were $64 \pm 8.8 \%$, $83 \pm 3.7 \%$, and $85 \pm 5.9 \%$, respectively.

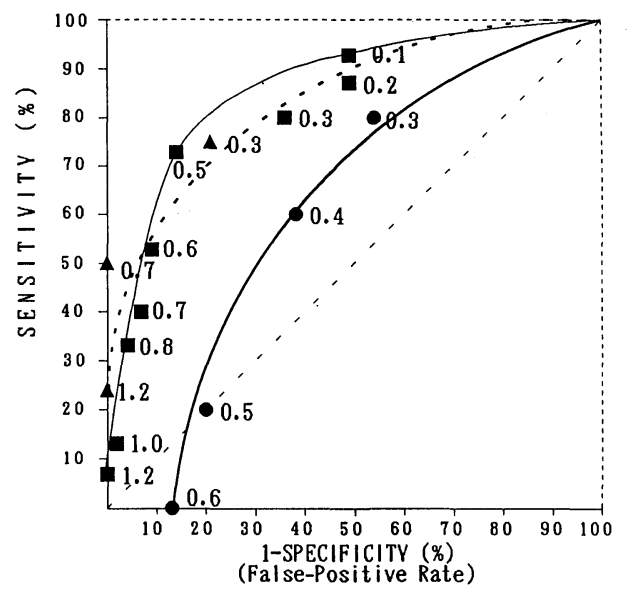

Fig. 4 ROC curves of urinary 3-Hyp for different age groups in stage 1 . The percentages of the areas under the ROC curves in adult, middle-aged and aged persons were $58 \pm 11.3 \%, 82 \pm 5.9 \%$, and $80 \pm 14.6 \%$, respectively. Legends are the same as those in Fig. 3.

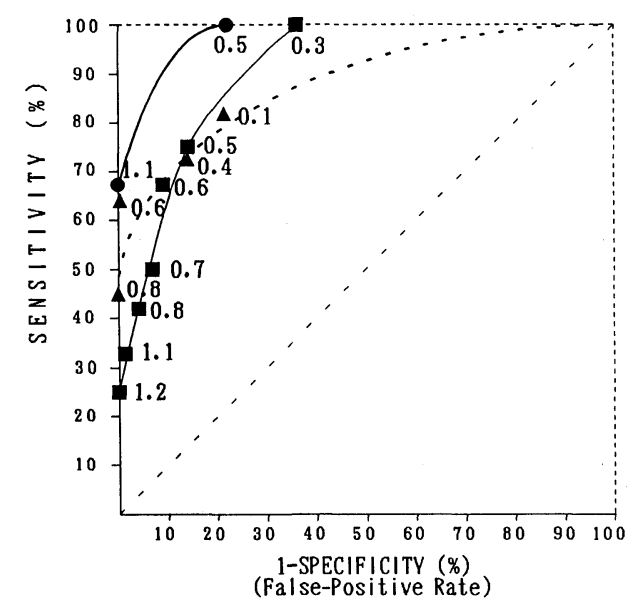

Fig. 5 ROC curves of urinary 3-Hyp for different age groups in stage 2 . The percentages of the areas under the ROC curves in adult, middle-aged and aged persons were $94 \pm 5.2 \%, 89 \pm 4.0 \%$, and $86 \pm 8.2 \%$, respectively. Legends are the same as in Fig. 3.

stage 1 of cancer were $80 \pm 14.6 \%$ and $82 \pm 5.9 \%$ respectively, for the aged and middle-aged groups, while the adult group showed an area of only $58 \pm 11$. $3 \%$. The ROC curves for stage 2 cancer (Figure 5) showed the adult group in the upper level, with $94 \pm$ $5.2 \%$, followed by the aged and middle-aged, with values of $89 \pm 4.0 \%$ and $86 \pm 8.2 \%$ respectively. Stage 3 of cancer showed almost the same level for all age groups: $85 \pm 12.8 \%$ for adults, $86 \pm 5.7 \%$ for middleaged and $83 \pm 9.7 \%$ for the aged.

The ROC curve for stomach cancer was lower than that for the other cancers, with an area of $75 \pm$ $4.4 \%$ versus $82 \pm 3.7 \%$.

\section{Discussion and conclusion}

Cancer screening in elderly persons presents many unsolved problems. Beside the fact that the risk of developing cancer is bigger than in younger adults ${ }^{7,15,16)}$, the rates of cancer screening in the elderly group is lower than in the younger group ${ }^{7,17}$. Robie, in his recent review of cancer screening in the elderly ${ }^{7}$, pointed out many barriers that affect the rates of cancer screening in this age group. The barriers included doubts of the physician and the 
patient about the efficacy, the cost-effectiveness, discomfort, and hazardousness that the cancer screening can provoke in the patient.

In this report we observed that in normal subjects the urinary excretion of 3-Hyp decreased with aging. However, in patients with cancer the linear regression of urinary 3-Hyp by age was almost horizontal. Figure 6 reproduces both linear regressions of 3-Hyp and aging in normal subjects (Figure 1) and in cancer patients (Figure 2), showing that cancer provoked an increase in the normal excretion of 3-Hyp. We also observed that the more advanced the age the more prominent the increase provoked by the cancer.

The cutoff point of $0.600 \mathrm{mg} / \mathrm{g}$ creatinine seemed to be the best threshold for cancer screening in persons aged 65 years or more, while the $0.800 \mathrm{mg} / \mathrm{g}$ creatinine appeared to be more applicable to middleaged and adult persons.

Using ROC curves for patients of all stages, we could observe that the distribution of age specific curves was clearly delimited. The highest sensitivity and specificity of the test were found for the aged group. The ROC curves obtained for each cancer stage showed that in the earliest stage the aged and middle-aged groups had better results. Advanced stages (2 and 3) showed smaller differences among the age groups. We conclude that urinary measurement of 3-Hyp has higher accuracy to detect cancer in the aged group in all stages of cancer together, and the aged and middle-aged groups have higher accuracy than for adults in early stages.

A putative cancer screening test must have some basic qualities: (1) it should not be affected by benign disease, and be negative in healthy subjects, (2) it must be positive only in persons with cancer, (3) it should be positive in treatable stages of the cancer, (4) it should be easy to collect samples for analysis, and (5) it should be cost effective. In our former report ${ }^{8)}$, we compared the urinary excretion of 3-Hyp and 4-Hyp (4-hydroxyproline) in healthy subjects and patients with nonmalignant diseases. Compared to 4-Hyp, 3-Hyp has a lower false-positive rate, $8 \%$, for nonmalignant diseases, compared to $21 \%$ for the other hydroxyproline. The effectiveness of the urinary 3-Hyp testing in this case control report, was greater in persons over 65, mainly in early (treatable) stages. With no discomfort, or hazards, and easy collection of samples for analyses, urinary 3-Hyp seems to be a good tool for screening cancer in the population, mainly in elderly persons, among whom cancer is more frequent.

The sensitivity of other cancer markers has been reported to be high in some organ cancers and low in others $^{8)}$. For instance, CA $19-9$ is elevated in $69 \%$ of pancreatic cancer patients, while for the carcinoembryonic antigen this proportion is $56 \%{ }^{18)}$. However, the sensitivity of CA 19-9 for colon cancer, in the high risk population ${ }^{19)}$, is $23 \%$ and carcinoembryonic antigen has been reported to have a sensitivity of $32 \%$ for lung cancer ${ }^{20)}$. Until now, no cancer marker has

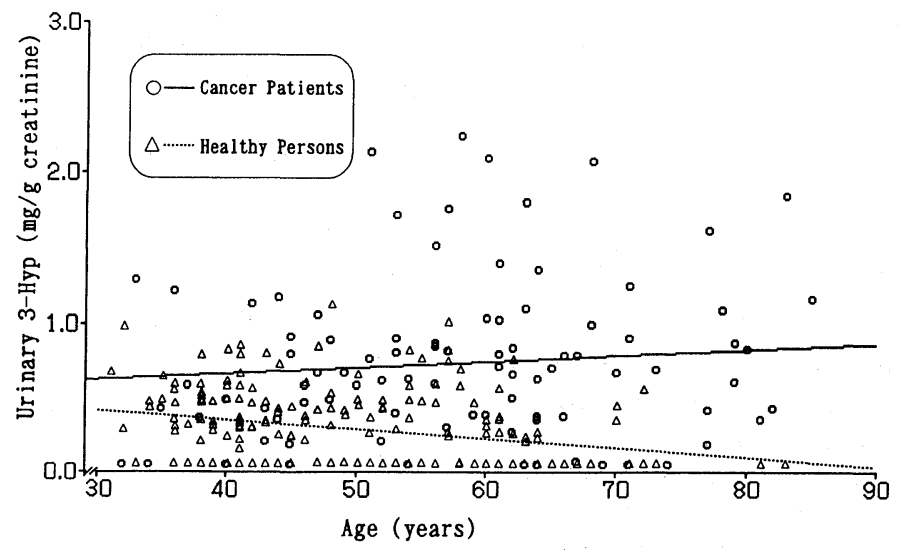

Fig. 6 Regression lines of urinary 3-Hyp and age for both cancer patients and healthy subjects. 
been shown to be applicable for an all purpose cancer screening test. Urinary 3 -Hyp is reported to have a good sensitivity for all kinds of studied cancers ${ }^{8)}$. This quality makes urinary 3-Hyp useful for screening cancer in the general population, and it could be utilized as part of an annual health-check program. The frequency of this health check should be determined by the increase of the sensitivity up to a reasonable level.

The authors stress the value of urinary 3-Hyp in cancer screening, mainly for the elderly, and it is important to verify the effectiveness of this test in a large population-based study.

\section{References}

1) Vital Statistics of Japan 1991, volume 1. Statistics and Information Department, Minister's Secretariat Ministry of Health and Welfare (1993).

2 ) Tominaga, S.: Trends in cancer mortality, incidence and survival in Japan, Jpn. J. Cancer Chemother., 19 (8 Suppl.), 1113-1120 (1992).

3 ) Hoel, D.G., Davis, D.L., Miller, A.B., Sondik, E.J. and Swerdlow, A.J.: Trends in cancer mortality in 15 industrialized countries, 1969-1986, Journal of the National Cancer Institute, 84, 313-320 (1992).

4) Mauer, A.M.: Editorial: Biologic markers for cancer: the search for the Holy Grail continues, J. Lab. Clin. Medicine, 120, 828-830 (1992).

5 ) Mant, D. and Fowler, G.: Mass screening: theory and ethics, Br. Med. Journal, 300, 916-918 (1990).

6 ) Roulston, J.E.: Limitations of tumor markers in screening, Br. J. Surgery, 77, 961-962 (1990).

7 ) Robei, P.W.: Cancer screening in the elderly, JAGS, 37, 888-893 (1989).

8 ) Okazaki, I., Matsuyama, S., Suzuki, F., Maruyama, K., Maruta, A., Kubochi, K., Yoshino, K., Kobayashi, Y., Abe, O. and Tsuchiya, M.: Endogenous urinary 3-hydroxyproline has $96 \%$ specificity and $44 \%$ sensitivity for cancer screening, J. Lab. Clin. Med., 120, 908-920 (1992).

9) Kefalides, N.A.: Structure and biosynthesis of basement membrane, Int. Rev. Connect Tissue Res., 6, 63-104 (1973).
10) Weiss, M.T., Weninger, M., Haeusler, J. and Lubec, G.: The determination of urinary 3-transhydroxyproline (3OHP). II.normal values in neonates, infants and preschool children, Pädiatrie und Pädologie, 23, 109-114 (1988).

11) Mays, P.K., McAnulty, R.J., Campa, J.S. and Laurent, G.J.: Age-related changes in collagen synthesis and degradation in rat tissues: Importance of degradation of newly synthesized collagen in regulating collagen production, Biochem J., 276, 307-313 (1991).

12) Egan, J.P.: Signal Detection Theory and ROC Analysis, Academic Press, New York (1975).

13) Metz, C.E.: Basic principles of ROC analysis, Seminars in Nuclear Medicine, 8, 283-298 (1982).

14) Hanley, J.A. and McNeil, B.J.: The meaning and use of the area under a receiver operating characteristic (ROC) curve, Radiology, 143, 26-36 (1982).

15) Schonwetter, R.S.: Geriatric oncology, Primary Care, 19, 451-463 (1992).

16) Warnecke, R.B.: The Elderly as a Target Group for Prevention and Early Detection of cancer, In "Cancer in the Elderly: Approaches to Early Detection and Treatment"(Editors: Yancik, R. and Yates, J.W.), pp.3-14, Springer, New York (1989).

17) Grover, S.A., Cook, E.F., Adam, J., Coupal, L. and Goldman, L.: Delayed diagnosis of gynecologic tumors in elderly women: relation to national medical practice patterns, Am.J. Medicine, 86, 151-157 (1989).

18) Ohshio, G., Manabe, T., Watanabe, Y., et al: Comparative studies of DU-Pan-2, carcinoembryonic antigen, and CA $19-9$ in the serum and bile of patients with pancreatic and biliary tract diseases: evaluation of the influence of obstructive jaundice, Am. J. Gastroenterology, 85, 1370 -1376 (1990).

19) Goldberg, E.M., Simunovic, L.M., Drake, S.L., et al: Comparison for serum CA 19-9 and CEA levels in a population at high risk for colorectal cancer, Hybridoma, 8, 569-575 (1989).

20) Lee, Y.C., Chang, K.J., Lu, F.J. and Yang, P.C.: Serum macro creatinine kinase type as a tumor 
日衛誌(Jpn. J. Hyg.) 第 49 巻 第 4 号 1994 年 10 月

marker in lung cancer: comparison with car-

Chih, 89, 104-109 (1990).

cinoembryonic antigen, Taiwan J. Hsueh Tsa

（受付 1994 年 1 月 10 日 受理 1994 年 5 月 16 日） 